\title{
EDITORIAL
}

\section{Quality of life, stage severity and COPD}

\author{
C. Jenkins* and R. Rodríguez-Roisin ${ }^{\#}$
}

or a long time now, arbitrary boundaries have been used in the severity grading of chronic airflow limitation and chronic obstructive pulmonary disease (COPD). The lack of validation of these severity cut-points has been widely criticised, predominantly because they are based on clinical impressions and simplistic metrics. This is acknowledged by the Global Initiative of Chronic Obstructive Lung Disease (GOLD) guidelines, which state that "There is only an imperfect relationship between the degree of airflow limitation and the presence of symptoms. Spirometric staging, therefore, is a pragmatic approach aimed at practical implementation and should only be regarded as an educational tool and a general indication to the initial management" [1]. Evidence that the GOLD cut-points are inappropriate, however, has not been forthcoming despite the strongly held views that the divisions for airflow limitation into a convenient gradation from mild to very severe may only relate very loosely to the degree of functional impairment and the prognosis of COPD $[2,3]$.

We should ask why clinicians consider it important to determine clinical disease severity. The most obvious answer is to assess disease severity in order to optimise treatment, compare management with recommended best practice, help patients plan for the increasing disability associated with COPD and, when appropriate, to facilitate timely discussion of end-of-life issues [4-6]. Prior to the availability of spirometry, clinicians might have determined severity on the basis of the severity of breathlessness, chest radiographical changes and/ or the development of complications, such as polycythaemia and cor pulmonale. These outcomes, defined as "consequences of the underlying disorders in COPD that are experienced directly by patients" [7] are relatively insensitive for assessing COPD severity. In contrast, spirometry offered the possibility of a reliable, sensitive test thought to reflect the disease process and which was known to worsen as patients deteriorated clinically $[8,9]$. Forced expiratory volume in one second (FEV1) correlates with mortality risk in patients with and without lung disease [10,11] and, although less closely than was initially assumed, also with a range of other important COPD outcomes, including exacerbation risk, hospitalisation, quality of life, body mass index and exercise capacity [12-15]. Thus,

${ }^{*}$ Woolcock Institute of Medical Research, Sydney, Australia. ${ }^{\text {\# }}$ Servei de Pneumologia (Institut del Tòrax), Hospital Clínic, Institut d'Investigacions Biomédiques August Pi i Sunyer (IDIBAPS), Ciber Enfermedades Respiratorias, Universitat de Barcelona, Barcelona, Spain.

STATEMENT OF INTEREST: A statement of interest for R. Rodríguez-Roisin can be found a www.erj.ersjournals.com/misc/statements.dtl

CORRESPONDENCE: C. Jenkins, Woolcock Institute of Medical Research, PO Box M77, Missenden Road, Camperdown NSW 2050, Australia. Fax: 61 291140014. E-mail: crj@med.usyd.edu.au the measurement of airflow limitation by spirometry became the default measurement for assessment of severity of COPD. Only recently, with epidemiological and clinical studies showing relatively weak correlations between FEV1 and some COPD outcomes, combined with concerns about COPD overdiagnosis due to the likelihood of an abnormal FEV1/forced vital capacity (FVC) ratio increasing with age in otherwise healthy people [16], have the weaknesses of spirometry as a measure of disease severity been fully appreciated. With the understanding of COPD as a chronic airways disease with systemic manifestations or comorbidities, and the obvious advantages of measuring patient-centred outcomes, FEV1 appears limited as a marker of COPD severity. Despite this, major regulatory agencies still request the use of FEV1 as a primary outcome for COPD randomised controlled trials. Given these problems, it is important to better understand the relationship between the current recommendations for assessment of severity based on FEV1, such as in the GOLD guidelines [1] and in the American Thoracic Society/ European Respiratory Society guidelines [17] and other outcomes known to reflect disease progression, clinical impairment and risk of exacerbations.

One of the most widely accepted umbrella measures of the impact of the disease is the measurement of health status by different tools, such as the St George's Respiratory Questionnaire (SGRQ) [18]. Health-status assessment is frequently included in clinical trials as a co-primary end-point to assess treatment and management interventions in COPD. It has a high degree of relevance to the patient compared with many of the other pathophysiological measurements made by clinicians, but one of the difficulties with health status assessment is its limited applicability in day-to-day clinical practice, despite the SGRQ having components of symptoms, activity and impacts which are important disease manifestations experienced by patients [19].

In the current issue of the European Respiratory Journal, WEATHERALl et al. [20] address this issue, demonstrating an association between the FEV1/FVC ratio and health status as measured by the SGRQ in a randomly selected population sample from New Zealand. Using receiver operating characteristic (ROC) curve analyses, WEATHERALL et al. [20] conclude that the use of a fixed post-bronchodilator FEV1/FVC ratio of 0.7 to define COPD is well supported by SGRQ measurements. Moreover, by applying a sophisticated statistical analysis to account for outliers, they found that the relationship between worsening SGRQ and reduced post-bronchodilator FEV1 was essentially linear below $80 \%$ predicted. Because cut-points of $80 \%, 60 \%$ and $40 \%$ for post-bronchodilator FEV1 related in a linear fashion to the SGRQ score more closely than the current 
GOLD cut-points, WEATHERALL et al. [20] propose that the GOLD severity stages would be better set at these thresholds. In favour of these FEV1 thresholds, WEATHERALL et al. [20] bring up the similarity with those widely used and promulgated by the Global Initiative for Asthma guidelines for bronchial asthma [21]. This may have immediate appeal, although the assessment of severity cannot be limited to an overly simplistic single dimension measure, such as FEV1, for asthma or COPD.

WEATHERALL et al. [20] claim that their study has the strength of being community based and as such not subject to bias created using outpatient populations or affected by high disease prevalence or comorbidities. Nevertheless, they recognise that the high prevalence of asthma in New Zealand makes it possible that some subjects identified as having COPD from postbronchodilator spirometry actually had asthma with relatively fixed airway narrowing, with or without coexisting COPD.

However, there are other important limitations in this study that need to be highlighted [20]. There are fewer data points of people with severe airflow obstruction and the scatter of SGRQ scores is very wide in relation to either FEV1/FVC or FEV1\% pred. Because of this, a robust statistical analysis was used, which provided regression lines with confidence limits that included only a minority of subjects. This introduces uncertainty that individual patients seen in real-life clinical practice are reliably classified using these criteria. Moreover, the results of ROC analysis show that the accuracy of prediction of FEV1/ FVC cut-points by SGRQ is poor, which again makes the practical applicability to individual patients problematic. Finally, the study does not show that the fixed cut-points arbitrarily chosen for FEV1/FVC are better than, or equivalent to, the lower limit of normality derived from the 95th percentile of the frequency distributions of a reference population [22].

In summary, the study by WEATHERALL et al. [20] confirms that the severity of chronic obstructive pulmonary disease based on post-bronchodilator forced expiratory volume in one second is related to health status as assessed by the St George's Respiratory Questionnaire in a community sample. The correlations with the St George's Respiratory Questionnaire are most convincing for milder grades of chronic obstructive pulmonary disease severity as defined by the Global Initiative of Chronic Obstructive Lung Disease staging criteria. However, in light of recommendations that the use of the lower limit of normal of the forced expiratory volume in one second/forced vital capacity ratio minimises the misclassification of airway obstruction [23], it will be important to determine whether this has similar or stronger associations with the St George's Respiratory Questionnaire and other important disease outcomes in chronic obstructive pulmonary disease. In any case, due to the noisy nature of the St George's Respiratory Questionnaire and its loose association with spirometry shown in this study, these data should not be used to infer health status from spirometry or vice versa in individual patients.

\section{REFERENCES}

1 Rabe KF, Hurd S, Anzueto A, et al. Global Strategy for the Diagnosis, Management, and Prevention of Chronic Obstructive Pulmonary Disease. GOLD Executive Summary. Am J Respir Crit Care Med 2007; 176: 532-555.
2 Antonelli-Incalzi R, Imperiale C, Bellia V, et al. Do GOLD stages of COPD severity really correspond to differences in health status? Eur Respir J 2003; 22: 444-449.

3 Mannino DM, Davis KJ. Lung function decline and outcomes in an elderly population. Thorax 2006; 61: 472-477.

4 Spencer S, Calverley PMA, Burge PS, Jones PW. Health status deterioration in patients with chronic obstructive pulmonary disease. Am J Respir Crit Care Med 2001; 163: 122-128.

5 Voll-Aanerud M, Eagan TML, Wentzel-Larsen T, Gulsvik A, Bakke PS. Respiratory symptoms, COPD severity, and health-related quality of life in a general population sample. Respir Med 2008; 102: 399-406.

6 Peto R, Speizer FE, Cochrane AL, et al. The relevance in adults of air-flow obstruction, but not of mucus hypersecretion, to mortality from chronic lung disease. Results from 20 years of prospective observation. Am Rev Respir Dis 1983; 128: 491-500.

7 Jones PW, Agusti AGN. Outcomes and markers in the assessment of chronic obstructive pulmonary disease. Eur Respir J 2006; 27: 822-832.

8 Anthonisen NR. Prognosis in chronic obstructive pulmonary disease. Am Rev Respir Dis 1986; 133: 14-20.

9 Burrows B. Predictors of loss of lung function and mortality in obstructive lung diseases. Eur Respir Rev 1991; 1: 340-345.

10 Knuiman MW, James AL, Divini ML, Ryan G, Bartholomew HC, Musk AW. Lung function, respiratory symptoms and mortality: results from the Busselton Health Study. Ann Epidemiol 1999; 9: 297-306.

11 Schünemann HJ, Dorn J, Grant BJ, Winkelstein W Jr, Trevisan M. Pulmonary function is a longterm predictor of mortality in the general population. Chest 2000; 118: 656-664.

12 Tojo N, Ichioka M, Chida M, Miyazato I, Yoshizawa Y, Miyasaka N. Pulmonary exercise testing predicts prognosis in patients with chronic obstructive pulmonary disease. Intern Med 2005; 44: 20-25.

13 Watz H, Washki B, Meyer T, Magussen H. Physical activity in patients with COPD. Eur Respir J 2009; 33: 262-272.

14 Montes de Oca MM, Talamo C, Perez-Padilla R, et al. Chronic obstructive pulmonary disease and body mass index in five Latin American cities: the PLATINO study. Respir Med 2008; 102: 602-650.

15 Osman IM, Gordon DJ, Friend JA, Legge JS, Douglas JG. Quality-of-life in hospital readmission in patients with chronic obstructive pulmonary disease. Thorax 1997; 52: 67-71.

16 Hardie JA, Buist AS, Vollmer WM, Ellingsen I, Bakke PS, Morkve O. Risk although the diagnosis of COPD in asymptomatic elderly never smokers. Eur Respir J 2002; 20: 1117-1122.

17 Celli BR, MacNee W W, ATS/ERS Task Force, Standards for the diagnosis and treatment of patients with COPD: a summary of the ATS/ERS position paper. Eur Respir J 2004; 23: 932-946.

18 Jones PW. Interpreting thresholds for a clinically significant change in health status in asthma and COPD. Eur Respir J 2002; 19: 398-404.

19 Domingo-Salvany A, Lamarca R, Ferrer M, et al. Healthrelated quality of life and mortality in patients with chronic obstructive pulmonary disease. Am J Respir Crit Care Med 2002; 166: 680-685.

20 Weatherall M, Marsh S, Shirtcliffe P, Williams M, Travers J, Beasley R. Quality of life measured by the St. George's 
Respiratory Questionnaire and spirometry. Eur Respir J 2009; 33: 125-130.

21 Bateman ED, Hurd SS, Barnes PJ, et al. Global strategy for asthma management and prevention: GINA executive summary. Eur Respir J 2008; 31: 143-178.
22 Pellegrino R, Viegi G, Brusasco V, et al. Interpretative strategies for lung function tests. Eur Respir J 2005; 26: 948-968.

23 Swanney MP, Ruppel G, Enright PL, et al. Using the lower limit of normal for the FEV1/FVC ratio reduces the misclassification of airway obstruction. Thorax 2008; 63: 1046-1051. 